\title{
Optimizing production of a biopesticide protectant by black yeast
}

\author{
Hany Saleh ${ }^{1}$, Ahmed Abdelrazak ${ }^{1 *}$, Ashraf Elsayed', Hisham El-Shishtawy ${ }^{2}$ and Yehia Osman ${ }^{1}$
}

\begin{abstract}
Natural protection of the Bacillus thuringiensis-based biopesticides from inactivation by the UV component of the cosmic rays constitutes a big challenge to environmentalists, health concerned groups, and industry. Melanin pigment produced by a variety of microbes has the capabilities of protecting these types of biopesticides. A black melanin produced by a locally isolated strain of the yeast Hortaea werneckii EGYNDA08 possesses the qualities of a sun protectant agent. This UV bio-protectant increased the killing potency of a locally isolated B. thuringiensis subsp. aegypti (Bt-C18)-based biopesticide ninefold upon feeding the first instar larvae of the cotton leaf worm, Spodoptera littrolis. This black melanin was extracted, characterized, and exposed to different optimization process for the purpose of enhancing its productivity. The optimization process employed medium engineering techniques to generate a suitable cheap production medium not only at bench-scale level but also at the bioreactor level. These optimization techniques have led to increase the melanin produced by the local isolate of Hortaea werneckii EGYNDA08 up to $228 \mathrm{mg} / \mathrm{l}$ compared to $8 \mathrm{mg} / \mathrm{l}$ prior to optimization. This study concluded that black yeast melanin could be used at a wide range as a potential green alternative for the conventional chemically based sunscreens that currently used to protect biopesticides from inactivation by the cosmic rays.
\end{abstract}

Keywords: Bacillus thuringiensis, Melanin, Black yeast, Biopesticide protectant

\section{Background}

Melanin refers to natural dark brown to black high molecular weight pigment which is usually complexed with carbohydrates and proteins. It produced by many living organisms as a polymer of oxidized tyrosine. There are three main types of melanin: eumelanin, pheomelanin, and allomelanin. Fungal melanin existed in the cell wall or as extracellular polymers formed by auto-oxidation of phenolic compounds or enzymatically using enzymes such as tyrosinase or polyketide synthase for 3,4-dihydroxyphenylalanine (DOPA) or 1,8-dihydroxynaphthalene (DHN) melanin biosynthesis respectively (Kutty 2009). The phenolic compounds that the fungal melanin is derived from include, tyrosine via DOPA in some groups of fungi and acetyl CoA via DHN melanin in ascomycetes and related asexual fungi and $\gamma$-glutaminyl3,4-dihydroxy-benzene or catechol in basidiomycetes.

\footnotetext{
*Correspondence: Ahmed_bt@mans.edu.eg

${ }^{1}$ Botany Department, Faculty of Science, Mansoura University, Mansoura

355111, Egypt

Full list of author information is available at the end of the article
}

The main melanin producers among the fungus world include Cryptococcus neoformans, Aspergillus niger, and Penicillium marneffei in addition to black yeast such as Wangialla dermatitis and Hortaea werneckii (Youngchim et al. 2004).

Melanin was reported to have specific role in the capacity of fungi to withstand extreme environments including radiation resistance (Zhdanova et al. 2000), protection against enzymatic lysis (Butler and Lachance 1987), oxidizing agents (Jacobson et al. 1995), extreme temperatures (Rosas and Casadevall 1997), osmotic stress (Ravishankar et al. 1995), and high concentrations of salts and detergents and the high heat (Zalar et al. 2011).

Distinctive properties of melanin suggest wide environmental and medical applications. Fungal melanin has gained more interest for their potential in many fields of biomedicine, dermocosmetics, nanotechnology, and materials science. Radiation was used in medical treatment like radio-immunotherapy or therapy by external beam that can effect on bone marrow and this was considered as a harmful side effect for using radiation; many experiments estimate that melanin was successfully used to protect bone 
marrow from such side effect (Schweitzer et al. 2010). In cosmetic industry, melanin gained great interests due to its ability to protect skin against the serious effects of UV radiation (Solano 2014). Some microorganisms can exhibit a common strategy in response to UV radiation including the synthesis and accumulation of UV light absorbing secondary metabolites that act as sunscreens (Garcia-Pichel and Castenholz 1991; Garcia-Pichel and Castenholz 1993); melanin was known as the best secondary metabolites that act as sunscreens Kollias et al. 1991). Microbial melanin pigment, especially from marine species, is an attractive option for researchers and industries because it is safer, easily degradable, and eco-friendly and does not cause harmful effects (Pombeiro-Sponchiado et al. 2017).

In the present work, a local black yeast strain namely Hortaea werneckii EGYNDA08 was previously isolated from halophilic Egyptian habitat and holds high potentiality for melanin production. The produced melanin was characterized, and its yield was enhanced via placket-Burman matrix and subsequently a central composite design algorithm. The produced melanin was found to be efficient in protecting Bacillus thuringensis-based biopesticide from deactivation by solar light.

\section{Materials and methods}

\section{Strains and growth conditions}

Hortaea werneckii EGYNDA08 (Elsayed et al. 2016) was previously isolated from Egyptian local habitats. The strain's colonies were found to be dark brown in color indicating the astronomical potentiality to produce melanin pigment. The used strain was isolated from water samples and collected from solar salter on the Mediterranean Sea coast in Egypt, exactly from Gamasa shore on Gamasa-Baltim road (latitude and longitude are 31.47 and 31.46 respectively) in November 2013. The isolate was grown on liquid minimal media prepared for cultivation of black yeast (Gunde-Cimerman et al. 2000).

\section{Pigment extraction}

Melanin "the black pigment" was subjected for extraction and purification from black yeasts as per Gadd (1982). After a week of growth, the culture was centrifuged at 10,000 rpm for $10 \mathrm{~min}$, supernatant was discarded and pellets were washed by distilled water and collected to be used for the extraction. Melanin was extracted by autoclaving the yeast harvested biomass with $1 \mathrm{~N} \mathrm{NaOH}$ (20 min, $121{ }^{\circ} \mathrm{C}$, at pressure $1.5 \mathrm{bar}$ ). The treated biomass was centrifuged for $10 \mathrm{~min}$ at $8000 \mathrm{rpm}$, and the developed supernatant contained the desired melanin pigment. Subsequently, melanin was precipitated by adding concentrated $\mathrm{HCl}$ until $\mathrm{pH} 2$ and then centrifuged at 10,000 rpm for $10 \mathrm{~min}$. Melanin was finally dried in dehumidified atmosphere.

\section{Characterization of melanin pigment}

The extracted pigment from $H$. werneckii EGYNDA08 was characterized by certain chemical and physical tests including the following:

- Chemical properties are used to define the extracted pigment as melanin was declared methods described by Thomas (1955). The solubility of the extracted pigment was examined in different common solvents such as distilled deionized water, $\mathrm{HCl}, \mathrm{NaOH}$, ethanol, methanol, chloroform, acetone, and benzene. Bleaching test was performed by various oxidizing agents like $\mathrm{H}_{2} \mathrm{O}_{2}$ and $\mathrm{KMnO}_{4}$ and also by reducing agents like $\mathrm{H}_{2} \mathrm{~S}$, besides resistance of degradation by concentrated acids. Precipitation of the pigment was examined by $1 \%$ $\mathrm{FeCl}_{3}$.

- The extracted pigment was subjected to spectrophotometric analysis that was performed using UV-visible spectrophotometer in a broad range of wavelength of 200-800 nm using (SHIMADZU UV-160, Tokyo, Japan). Pigment was diluted 1:10 times using $1 \mathrm{~N}$ sodium hydroxide. Authentic melanin standard (Sigma Aldrich; reference M8631) was used as reference.

- Extracted pigment was recorded on IR spectrometer (Nicolet iS10, USA), and spectra were collected at the wave number region of $400-4000 \mathrm{~cm}$ using $\mathrm{KBr}$ pellets acquired by pressing under vacuum uniformly prepared mixtures of pigment sample and spectrometry grade $\mathrm{KBr}$. The result recorded was compared against authentic melanin standard (Sigma Aldrich, reference: M8631).

- Nuclear magnetic resonance (NMR) spectroscopy was recorded to the extracted pigment using a model (JEOL NMR ECA-500). The pigment was suspended in dimethyl sulfoxide (DMSO-d6). The proton NMR spectrum of the sample was obtained at $400 \mathrm{MHz}$ using a model (JEOL NMR ECA-500). The chemical shift scale was in parts per million (ppm).

\section{Effect of different sodium chloride concentrations on the growth of the isolate and melanin production}

Salinity test was performed to explore the effect of different sodium chloride concentrations on the production of melanin and growth by the isolate under investigation. Cells were grown on potato dextrose agar (PDA) medium which was supplied by different $\mathrm{NaCl}$ concentrations $0,2.5,5,10,15,20$, and $25 \%$. Fifty milliliters of liquid media inoculated by black yeast in $250 \mathrm{~mL}$ Erlenmeyer flask at $22{ }^{\circ} \mathrm{C}$ for a week in a rotary shaker at $170 \mathrm{rpm}$. After growth and the appearance of black color, the resulted melanin was extracted and estimated. 


\section{Screening of different medium components by Plackett-} Burman (PB) design

A PB screening experiment was performed to screen different carbon sources, nitrogen sources, and metal ions to test and compare their effect on the ability of the isolated strain to produce melanin.

A set of 12 experiments, with 10 variables and one dummy, was performed as generated by the software package and shown in Table 2 and each run had its unique composition. The screened medium components include four different carbon sources (sucrose, fructose, glycerol, and sugar cane molasses (SCM)), three different nitrogen sources (corn steep liquor, malt extract, and ram horn) in addition to three different metal ions $\left(\mathrm{NaCl}, \mathrm{MgSO}_{4}\right.$, and $\mathrm{K}_{2} \mathrm{HPO}_{4}$ ). The dummy variable was used to estimate the standard error of the experiments.

Each variable was investigated at a maximum (high) "+" level and a minimum (low) "-" level. Presence/absence principle was used to test the variables, as absence of variable was detected by low level which always considered as 0 and the maximum level was considered as $1 \mathrm{~g} / \mathrm{l}$ for carbon and nitrogen sources. But in case of metal ions, the minimum value was represented as half of the reported value; for $\mathrm{NaCl}, \mathrm{MgSO}_{4}$, and $\mathrm{K}_{2} \mathrm{HPO}_{4}$, the minimum value was $0,0.1$, and $1 \mathrm{~g} / \mathrm{l}$ respectively and maximum was $10,0.5$, and $2 \mathrm{~g} / \mathrm{l}$ respectively.

Experiments were performed in $250 \mathrm{ml}$ Erlenmeyer flasks containing $50 \mathrm{ml}$ of sea water and medium components according to every run; flasks were incubated in a $170 \mathrm{rpm}$ rotary shaker at $22{ }^{\circ} \mathrm{C}$ and $\mathrm{pH} 6$ for 1 week. Responses were measured in terms of growth and productivity of melanin $(\mathrm{mg} / \mathrm{l})$.

Comparison of the significance of each factor and its main effect on the growth of isolate $H$. werneckii EGYNDA08 and production of melanin is the main target of the screening experiment (Montgomery 2008).

Sugar cane molasses, corn steep liquor, and ram horn were waste materials obtained from agriculture and animal waste products, and they were tested as potential cheap components for the melanin medium production. Ram horn hydrolysis was performed as reported by Kurbanoglu and Kurbanoglu (2004).

\section{Optimizing central composite design (CCD) for medium composition}

The most significant variables resulted from $\mathrm{PB}$ design subsequently optimized via applying a central composite design algorithm to identify the optimum level of each of the tested variable. Applying a CCD experiment allowed capturing the main effect of each variable, quadretic effect, and interaction between them. The potential components of production medium were sugar cane molasses, corn steep liquor, malt extract, and glycerol. Both carbon sources, sugar cane molasses and glycerol, were tested in a range between 0 up to $10 \mathrm{~g} / \mathrm{l}$, with $5 \mathrm{~g} / \mathrm{l}$ representing the center point. In addition to the tested carbons sources, two different nitrogen sources were also tested in a range between 0 and $5 \mathrm{~g} / \mathrm{l}$, with $2.5 \mathrm{~g} / \mathrm{l}$ representing the tested center point.

A set of 31 experiments was performed as shown in Table 3, in $250 \mathrm{ml}$ Erlenmeyer flask containing $50 \mathrm{ml}$ of sea water and tested media combination prepared according to the design The initial $\mathrm{pH}$ was 6.0 for all flasks, and they were incubated at a $170 \mathrm{rpm}$ in rotary shaker incubator for a week.

The calculated responses were dry weight $(\mathrm{g} / \mathrm{l})$ for the growth and melanin productivity $(\mathrm{mg} / \mathrm{l})$. 3D surface plot was generated to facilitate understanding interaction between factors and estimate the optimum concentration of each component.

A second-order polynomial model was created for the estimation of the medium composition optimum production for melanin production (Eq. 1):

$$
Y=\beta_{0}+\Sigma \beta_{i} X_{i}+\Sigma \beta_{i i} X_{i i}+\Sigma \beta_{i j} X_{i j}
$$

where $\beta_{i}$ is the regression coefficients for individual factor effect, $\beta_{i i}$ is the regression coefficients for square effects of factor, and $\beta_{i j}$ is the regression coefficients for interaction between factors. The matrix applies and the analysis of variance (ANOVA) was carried out by Minitab 16 software. Validation experiments for CCD experiment were performed based on analysis result(s).

\section{Bioreactor batch cultivation}

A batch run was performed using bioreactor with a working volume of $400 \mathrm{ml}$. The main parts of the bioreactor set up are shown in Fig. 1. It was equipped with main bioreactor vessel (three-neck wolf flask) with total volume of $1 \mathrm{l}$, magnetic bar to supply agitation to the culture, air pump that ended by porous sparger to provide the culture with air (sterilized by disc filter capsule), cold light emitting source (Volpi, Intralux; 4100 EURO device), and external feed bottle that feed the vessel with seed culture. The cold light source was applied to study the effect of light and did not emit any heat to the system to avoid any extra heating generated due to light exposure.

The batch fermentation was stirred at $100 \mathrm{rpm}$, and incubation temperature was $22^{\circ} \mathrm{C}$. Air flow was abled all over the batch run to provide aeration $(1 \mathrm{l} / \mathrm{min})$. Seed culture was prepared with the same nutrient concentration resulted from the previously carried out CCD experiment and was found to be $40 \mathrm{ml}$ sea water, yeast extract $2 \mathrm{~g} / \mathrm{l}, \mathrm{NaCl} 10 \mathrm{~g} / \mathrm{l}, \mathrm{K}_{2} \mathrm{HPO}_{4} 1 \mathrm{~g} / \mathrm{l}$, sugar cane molasses $10 \mathrm{~g} / \mathrm{l}$, corn steep liquor $3.8 \mathrm{~g} / \mathrm{l}$, and malt extract $2.5 \mathrm{~g} / \mathrm{l}$. Samples were pulled at time intervals $24 \mathrm{~h}$ and 


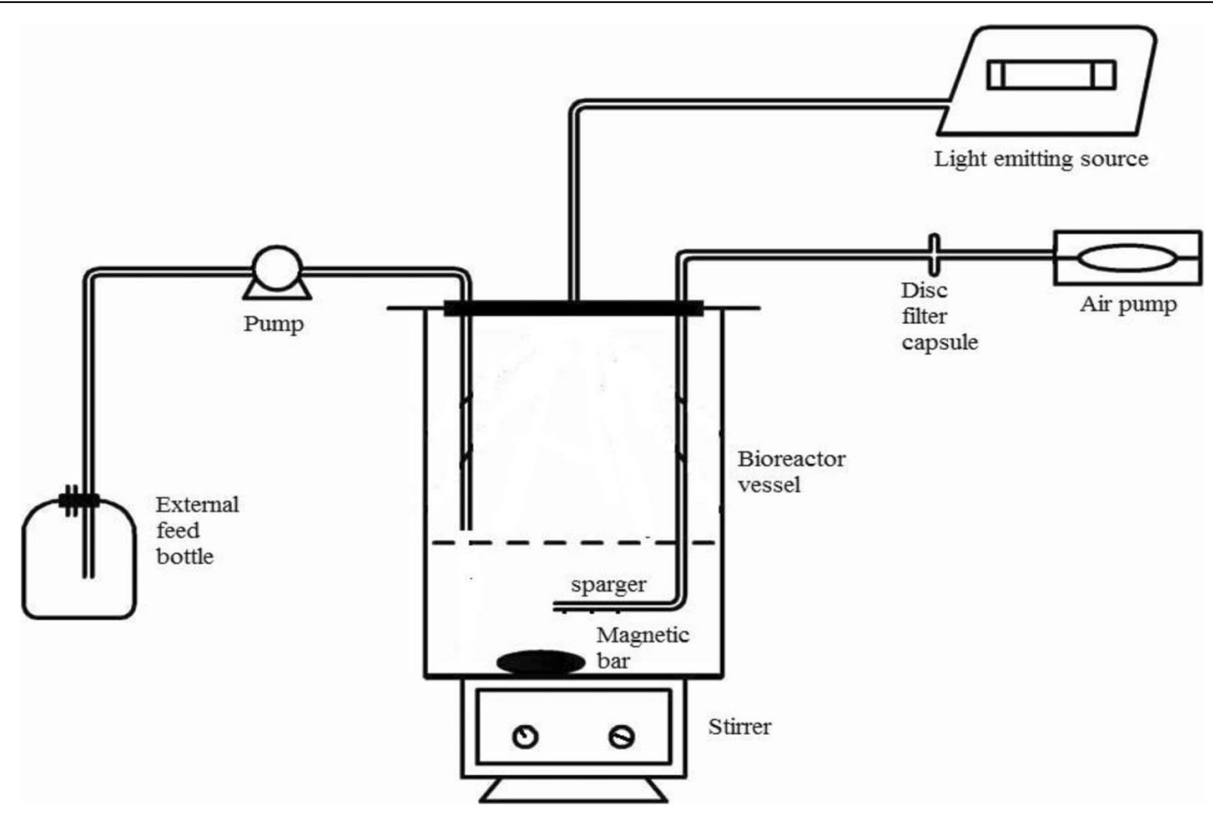

Fig. 1 Batch bioreactor set up

analyzed for growth (dry weight $\mathrm{g} / \mathrm{l}$ ) and melanin yield $(\mathrm{mg} / \mathrm{L})$.

Two-level fractional design was applied to study the effect of light on $H$. werneckii EGYNDA08 growth and production of melanin at the bioreactor scale. In terms of light effect, two variables were tested including brightness and intensity with two levels and one center point (The brightness levels were 0,50 , and 100 Lumin, while the intensity levels were 60,80 , and 100 Lux). The whole system and the media were sterilized prior to the start of the experiment, and the air was filtered via a sterile filter membrane to prevent any post contaminations.

\section{UV protection of $B$. thuringiensis subsp. aegypti-based biopesticides}

B. thuringiensis subsp. aegypti (Bt-C18) was one of Prof. Osman's collection, Agriculture Genetic Engineering Research Institute (AGERI), Agriculture Research Center, Giza, Egypt. This strain was deposited in the American Type Culture Collection (ATCC) since October 8, 1999, under the patent deposit designation number 55922. The bacterium was grown in T3 broth at $30{ }^{\circ} \mathrm{C}$ to sporulation stage. The harvested cellular pellet of the culture containing mixture of spores and crystal toxin were used throughout the study. Crude Bt-C18 spore-crystal complex was mixed with equal concentration of the black yeast melanin; these concentrations were 5,10 , and $15 \mathrm{ppm}$. Each of the mixtures was spread, as a thin film, on a glass plate $(20 \times 20 \mathrm{~cm})$ and left exposed to the direct sun (in a mid-August day, 2017) from 9 am to $3 \mathrm{pm}$, to get maximum exposure to UV. A non-melanin crude $B t$-C18 spore-crystal complex (control) was exposed to the direct sun in the same manner. Second instar larvae of S. littoralis were fed on an artificial diet supplied with either 5,10 , or $15 \mathrm{ppm}$ of the sun-exposed Bt spore-crystal complexes with or without melanin (Osman et al. 2014). Mortality of S. littoralis larvae were scored and compared to control insects.

\section{Statistical analysis}

All the one-way ANOVA was performed using Origin 8 statistical package, while all the multi-way ANOVA was performed using Minitab 16 statistical software package (Elrazak et al. 2013).

\section{Results and discussion}

Microbial melanin, with its unique features, constitutes a group of most interested pigments. It has recently gained global attention by pharmaceutical, cosmetics, electronic, and food processing industries d'Ischia et al. 2015). Microbial pigments gained their popularities from being more viable alternatives than pigments produced by animals or plants. These have no seasonal constraints and do not compete for farming land; moreover, the production of microorganisms is easily produced on cheap culture media (Kumar et al. 2015; Akilandeswari and Pradeep 2016). Additionally, melanin pigments were found to be easily degradable, safer for products, and more cost-effective than synthetic one.

In this research; $H$. werneckii EGYNDA08 was isolated from local Egyptian marine (salt marshes) habitat and was selected based on its dark black appearance, which reflected its capability to produce valuable melanin. This isolate was characterized at the classical and molecular 
levels, and it is the black melanin that was also chemically and physically characterized.

\section{Characterization of the melanin pigment}

The dark pigment extracted from the black yeast, $H$. werneckii EGYNDA08, was chemically characterized (Table 1). The data showed that the extracted pigment was soluble in sodium hydroxide (alkaline solvent) but not soluble in water or organic solvents (chloroform, ethanol, and acetone). It was precepitated using concentrated hydrochloric acid $(\mathrm{HCl})$, declorized by hydrogen peroxide $\left(\mathrm{H}_{2} \mathrm{O}_{2}\right)$, and exhibited positive reaction in presence of ferric chloride $\left(\mathrm{FeCl}_{3}\right)$.

The extracted black melanin pigment was also characterized using UV, FTIR, and NMR spectral analysis. The UV-visible absorbance $(200-800 \mathrm{~nm})$ spectrum of the extracted pigment and melanin standard (Sigma Aldrich) exhibited a strong absorbance in the UV region, and a characteristic peak was detected at $231 \mathrm{~nm}$ (Fig. 2a) for extracted melanin from $H$. wernekii EGYNDA08, which was highly similar to melanin standard peak at 236, suggesting the presence of phenol groups.

The FTIR spectrum of melanin extracted from $H$. wernekii EGYNDA08 (Fig. 2b) showed the peaks near $3448 \mathrm{~cm}^{-1}, 2928 \mathrm{~cm}^{-1}, 1633 \mathrm{~cm}^{-1}$, and $1264 \mathrm{~cm}^{-1}$ referred to the amino group $(\mathrm{NH})$, the $\mathrm{C}-\mathrm{H}$ stretch bond related to methane group, the amino group with $\left(\mathrm{NH}_{2}\right.$ stretching, and the anhydride group $(\mathrm{C}-\mathrm{O})$ in the extracted fungal pigment, respectively. The result was calibrated against melanin standard purchased from Sigma Aldrich.

The NMR analysis was performed for the extracted pigment to detect the structural composition. The proton NMR spectrum was estimated for the melanin sample that extracted from the isolate under study. The peaks that observed in the spectra were shown in (Fig. 2c) and was agreed with the characterization of DHN melanin in Kutty et al. 2013.

Table 1 Chemical characterization of extracted melanin from Hortaea werneckii

\begin{tabular}{ll}
\hline Test & Result \\
\hline Color & Black \\
Solubility in $\mathrm{H}_{2} \mathrm{O}$ & - \\
Solubility in $\mathrm{NaOH}$ & + \\
Solubility in organic solvents & - \\
(chloroform, ethanol, and acetone) & + \\
Precipitation with $\mathrm{HCl}$ & + \\
Decolorization by oxidants agents $\left(\mathrm{H}_{2} \mathrm{O}_{2}\right)$ & + \\
Precipitation for polyphenols with $\mathrm{FeCl}_{3}$ &
\end{tabular}

Positive (+) and negative (-) response
All chemical and physical characterizations have proved that the black pigment from the local isolate of H. wernekii EGYNDA08 was identical to the standard melanin purchased from Sigma Aldrich, with a catalog number M8631.

\section{Effect of salinity on microbial melanin production}

The isolate under investigation was halotolerant black yeast and can survive in a wide range of salinity. Effect of different concentration of sodium chloride was estimated on dry weight of growth and production of melanin by $H$. werneckii EGYNDA08. Dry weight and melanin production decreased by increasing the concentration of sodium chloride. Dry weight was 18.6, 17.5, 15.7, 10, 8.9, 3.1 and $1.5 \mathrm{~g} / \mathrm{l}$ for $0,2.5,5,10,15,20$, and $25 \%$ of $\mathrm{NaCl}$ respectively and $124,120,104,80,74,32,8 \mathrm{mg} / \mathrm{l}$ for melanin concentration.

H. werneckii is considered as the most extremely known salt-tolerant eukaryote, and it is resembled to Debaryomyces hansenii yeast species that can tolerate $\mathrm{NaCl}$ concentration up to $25 \%$. In this work, $H$. werneckii EGYNDA08 was found to be able to tolerate salt concentration up to $25 \%$, in nearly saturated salt concentration, although it showed a slow growth behavior. The isolate was also found to be able to grow over a wide range of $\mathrm{NaCl}$ concentrations and even in complete absence of salt. Melanin concentration decreased by increasing salinity because the growth medium affects melanization of $H$. werneckii; these results are in line with the results achieved by Gunde-Cimerman et al. (2000) and Kogej et al. (2004).

\section{Melanin production optimization}

Different medium components include carbon, nitrogen sources, and metal ions that commonly have a main role in a bio-reaction as they are directly linked with biomass and metabolite production and were screened for their significant effect on melanin production by $H$. werneckii EGYNDA08.

\section{Screening of different medium components using $P B$}

A screening PB experiment was carried out to detect the most significant medium components that could be subsequently optimized by applying central composite design to indicate the exact optimum combination. PB experiments with 11 variables were tested and reported that the obtained dry weight ranged from 0.8 (run 10) to $6.4 \mathrm{~g} / \mathrm{l}$ (run8) and melanin production ranged from 8.14 (run 10) to $117.83 \mathrm{mg} / \mathrm{l}$ (run 4) (Table 2).

The statistical analysis of the responses was performed using Minitab 16 software to detect the most significant factors that effect on growth and melanin production at $\alpha=0.1$ with level of confidence $90 \%$. Factors that had a $P$ value $\leq \alpha$ were considered to be significant. 

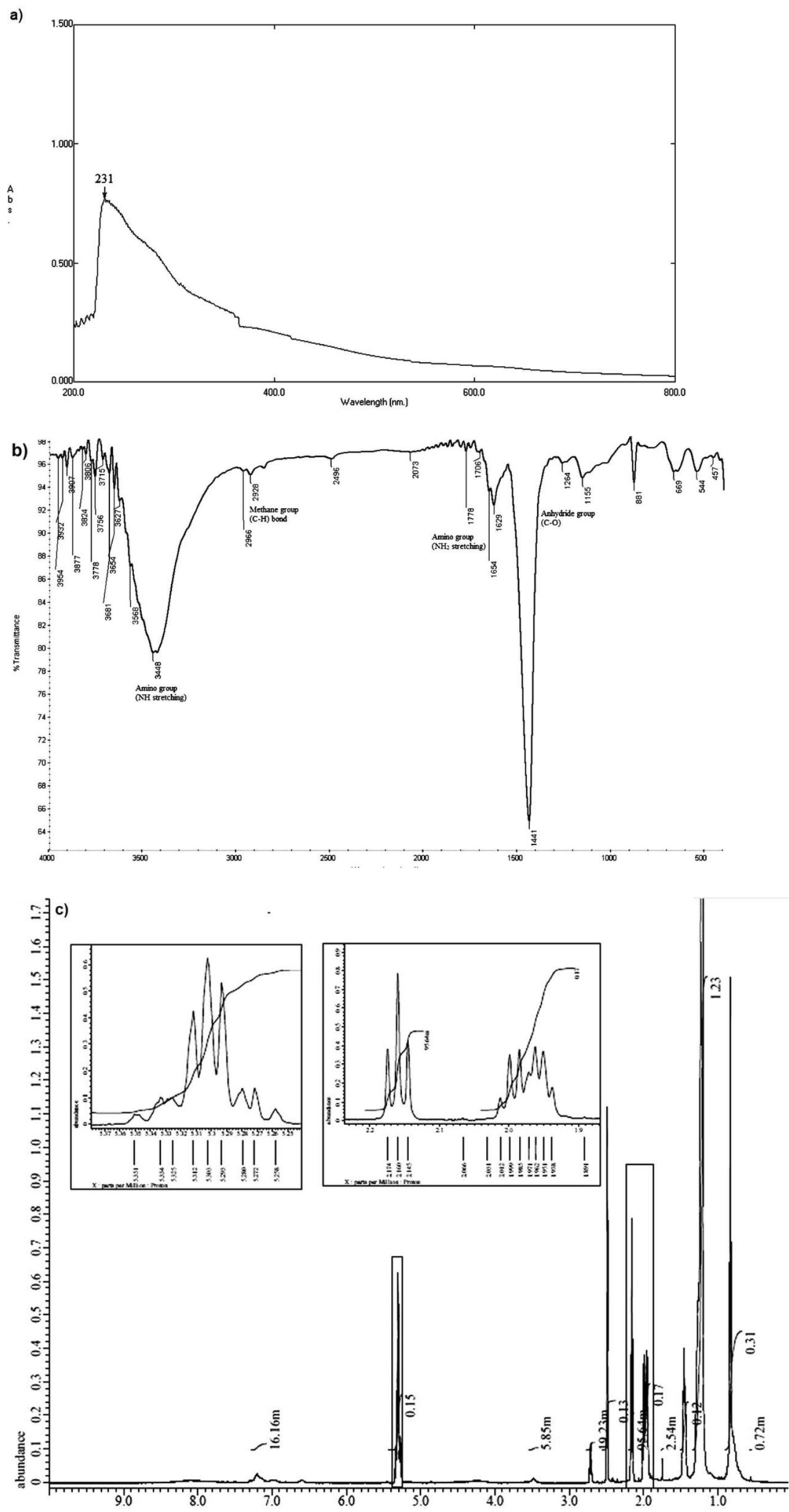

Fig. 2 Physical characterization of melanin extracted from Hortaea werneckii EGYNDA08. a UV-visible absorbance. b Infrared spectrum (FT-IR). c NMR analysis 
Table 2 The matrix and responses for the Plackett-Burman design for the tested isolate to explore the significant effect of different medium components on the melanin productivity

\begin{tabular}{|c|c|c|c|c|c|c|c|c|c|c|c|c|c|}
\hline \multirow[t]{2}{*}{ Run } & \multicolumn{11}{|c|}{ Variables } & \multicolumn{2}{|l|}{ Responses } \\
\hline & $x_{1}$ & $x_{2}$ & $x_{3}$ & $X_{4}$ & $x_{5}$ & $x_{6}$ & $x_{7}$ & $x_{8}$ & $X_{9}$ & $x_{10}$ & $X_{11}$ & Dry weight ( $\mathrm{g} / \mathrm{l})$ & Melanin (mg/l) \\
\hline 1 & - & - & - & + & + & + & - & + & + & - & + & 3.4 & 32.59 \\
\hline 2 & - & - & + & + & + & - & + & + & - & + & - & 5.2 & 87.74 \\
\hline 3 & - & + & - & - & - & + & + & + & - & + & + & 3.8 & 37.6 \\
\hline 4 & + & + & - & + & - & - & - & + & + & + & - & 4 & 117.83 \\
\hline 5 & - & + & + & - & + & - & - & - & + & + & + & 3.5 & 75.21 \\
\hline 6 & + & - & + & + & - & + & - & - & - & + & + & 4.9 & 68.94 \\
\hline 7 & + & - & + & - & - & - & + & + & + & - & + & 3.6 & 66.43 \\
\hline 8 & + & - & - & - & + & + & + & - & + & + & - & 6.4 & 110.31 \\
\hline 9 & + & + & + & - & + & + & - & + & - & - & - & 3.8 & 57.66 \\
\hline 10 & - & - & - & - & - & - & - & - & - & - & - & 0.8 & 8.14 \\
\hline 11 & - & + & + & + & - & + & + & - & + & - & - & 3.3 & 62.67 \\
\hline 12 & + & + & - & + & + & - & + & - & - & - & + & 4.6 & 116.57 \\
\hline
\end{tabular}

Maximum and minimum values were given as italics where $X_{1}$ symbolizes sucrose, $X_{2}$ symbolizes corn steep liquor, $X_{3}$ symbolizes $\mathrm{MgSO}_{4}, X_{4}$ symbolizes fructose, $X_{5}$ symbolize malt extract, $X_{6}$ symbolizes $\mathrm{K}_{2} \mathrm{HPO}_{4}, X_{7}$ symbolizes glycerol, $X_{8}$ symbolizes ram horn, $X_{9}$ symbolizes NaCL, $X_{10}$ symbolizes sugar cane molasses, and $X_{11}$ symbolizes dummy

Four variables were found having the most significant effects were chosen for central composite design to detect the optimum level of each one; these variables were sugar cane molasses, corn steep liquor, malt extract, and glycerol. These variables were significant and represented in the design as waste products collected from the local market and were expected to reduce the overall production cost.

The production cost is considered as the main drawback that faces any biotechnological process; optimization is considered as the most effective elucidation for this problem (Sangkharak and Prasertsan 2007). The statistical optimization approaches were proven to be a successful technique for investigation of multiple variables of a process because it make optimization process more easy with fewer trials of experiments (Bajaj et al. 2009; El Naggar et al. 2015).

\section{Central composite design to optimize the production medium composition}

Sugar cane molasses, corn steep liquor, malt extract, and glycerol were chosen as the potential cheap production medium components. CCD experiment was performed to indicate the optimum medium composition as previously mentioned. The matrix and responses of the design were shown in Table 3.

The maximum amount in growth (dry weight) was observed at run number 14 while the maximum melanin productivity was obtained at run number 16 . Analysis of variance of the linear, quadretic effect, and the interaction among factors were shown in Table 4 where factors with $P$ value $<0.1$ were considered as significant. The most significant factors that affected melanin productivity were the main effect of sugar cane molasses, glycerol, and corn step liquor, and quadretic effect of sugar cane molasses, malt extract, and glycerol.

ANOVA resulted from the main effect of each factor, the quadratic effect and interaction among them were shown in Table 4 . The $P$ value was estimated that the main effect of malt extract and glycerol were highly significant for the isolate growth, while sugar cane molasses, glycerol, and corn steep liquor were highly significant for melanin production. Also, the quadratic effect of corn steep liquor showed a significant effect on growth and production of melanin; on the other hand, the quadratic effect of sugar cane molasses, malt extract, and glycerol had a significant effect on melanin production. In addition, the interaction among malt extract and glycerol and between malt extract and corn steep liquor had a significant effect for isolate growth. Depending on the resulted mathematical model, the optimum combination of factors for maximum melanin productivity was evaluated as $10 \mathrm{~g} / \mathrm{l}$ sugar cane molasses, $3.8 \mathrm{~g} / \mathrm{l}$ corn steep liquor, and $2.5 \mathrm{~g} / \mathrm{l}$ malt extract. The maximum productivity obtained under these optimum conditions was $210 \mathrm{mg} / \mathrm{l}$.

\section{Effect of light on melanin production}

The growth and melanin productivity within batch bioreactor was obtained, and the result was calculated after $96 \mathrm{~h}$ from incubation of the reactor. The two-level FFD experiments were generated by Minitab 16 software; two variables were tested including brightness and intensity of the cold light source with two levels and one center point resulting in five runs (Table 5). Responses were measured for each of the performed run for H.werneckii 
Table 3 Matrix and responses of CCD for carbon and nitrogen sources optimization

\begin{tabular}{|c|c|c|c|c|c|c|}
\hline \multirow[t]{2}{*}{ Run } & \multicolumn{4}{|c|}{ Variables } & \multicolumn{2}{|l|}{ Responses } \\
\hline & SCM & Malt extract & Glycerol & CSL & Dry weight (g/l) & Melanin yield (mg/l) \\
\hline 1 & 2 & 2 & -2 & 2 & 3 & 90.88 \\
\hline 2 & 0 & 0 & 0 & 0 & 3.95 & 55.93 \\
\hline 3 & 0 & -1 & 0 & 0 & 5 & 29.30 \\
\hline 4 & 1 & 0 & 0 & 0 & 3.4 & 66.35 \\
\hline 5 & 2 & 2 & -2 & -2 & 3.5 & 77.01 \\
\hline 6 & 2 & -2 & 2 & -2 & 3.2 & 59.77 \\
\hline 7 & 0 & 0 & 0 & -1 & 0 & 0 \\
\hline 8 & -2 & 2 & 2 & 2 & 6 & 54.84 \\
\hline 9 & -2 & 2 & -2 & -2 & 3.5 & 35.09 \\
\hline 10 & 0 & 0 & 1 & 0 & 3.4 & 73.87 \\
\hline 11 & -2 & -2 & 2 & 2 & 2.2 & 61.18 \\
\hline 12 & 0 & 0 & 0 & 0 & 3.95 & 55.93 \\
\hline 13 & -1 & 0 & 0 & 0 & 3.5 & 78.34 \\
\hline 14 & 2 & 2 & 2 & -2 & 10 & 39.17 \\
\hline 15 & -2 & 2 & -2 & 2 & 2.5 & 68.0 \\
\hline 16 & 2 & -2 & -2 & 2 & 4 & 97.14 \\
\hline 17 & 0 & 0 & 0 & 1 & 3.4 & 82.10 \\
\hline 18 & 2 & -2 & 2 & 2 & 4 & 77.56 \\
\hline 19 & 0 & 0 & 0 & 0 & 3.95 & 55.93 \\
\hline 20 & -2 & 2 & 2 & -2 & 5 & 17.39 \\
\hline 21 & 0 & 1 & 0 & 0 & 3.1 & 49.90 \\
\hline 22 & -2 & -2 & -2 & -2 & 1.4 & 56.48 \\
\hline 23 & 0 & 0 & 0 & 0 & 3.95 & 55.93 \\
\hline 24 & 2 & -2 & -2 & -2 & 3.3 & 62.67 \\
\hline 25 & 2 & 2 & 2 & 2 & 3.1 & 76.30 \\
\hline 26 & -2 & -2 & 2 & -2 & 2.2 & 37.60 \\
\hline 27 & -2 & -2 & -2 & 2 & 3 & 63.22 \\
\hline 28 & 0 & 0 & 0 & 0 & 3.95 & 55.93 \\
\hline 29 & 0 & 0 & 0 & 0 & 3.95 & 55.93 \\
\hline 30 & 0 & 0 & 0 & 0 & 3.95 & 55.93 \\
\hline 31 & 0 & 0 & -1 & 0 & 6.1 & 71.60 \\
\hline
\end{tabular}

Maximum and minimum yields were displayed as italics

EGYNDA08 including growth optical density $(600 \mathrm{~nm})$, dry weight (g/l), pH variability, and melanin yield (mg/l).

The main effect plot (Fig. 3a, b) was generated to detect the optimum values of brightness and intensity on the calculated responses. As shown in Table 5, the optimum levels of brightness and intensity were $50 \%$ lumin and $80 \%$ lux respectively. Within the bioreactor environment, in addition to the lighting conditions, the amount of melanin produced was found to be $228 \mathrm{mg} / \mathrm{l}$ representing approximately fivefold increase compared to the amount produced prior to optimization. A validation experiment was carried out, within bioreactor, under the proposed light conditions, and samples were withdrawn over time for the purpose of monitoring the growth and the yield of melanin under the achieved optimum conditions.

The growth was measured as optical density, dry weight, and $\mathrm{pH}$ of medium were measured under both light and dark conditions (Fig. 4).

As shown in Fig. 4, light conditions had a significant role on the growth of $H$. werneckii EGYNDA08 and melanin yield as the dry weight was increased up to $7.4 \mathrm{~g} / \mathrm{l}$ and melanin yield was $228 \mathrm{mg} / \mathrm{l}$ in compared to $6.2 \mathrm{~g} / \mathrm{l}$ and $160 \mathrm{mg} / \mathrm{l}$ for dry weight and melanin yield in dark conditions. 
Table 4 ANOVA for CCD experiment at confidence level 90\%

\begin{tabular}{|c|c|c|c|c|c|c|}
\hline \multirow[t]{3}{*}{ Variable } & \multicolumn{6}{|l|}{ Responses } \\
\hline & \multicolumn{3}{|l|}{ dry weight $(\mathrm{g} / \mathrm{l})$} & \multicolumn{3}{|l|}{ Melanin (mg/l) } \\
\hline & Sum of squares & $F$ value & $P$ value & Sum of squares & $F$ value & $P$ value \\
\hline A:sugar cane molasses & 4.060 & 2.10 & 0.167 & 1927 & 9.68 & 0.007 \\
\hline B:malt extract & 8.843 & 4.57 & 0.048 & 118.9 & 0.60 & 0.451 \\
\hline C:glycerol & 5.838 & 3.01 & 0.102 & 939.3 & 4.72 & 0.045 \\
\hline D:corn steep liquor & 0.305 & 0.16 & 0.697 & 3834.2 & 19.26 & 0.000 \\
\hline$A^{2}$ & 0.001 & 0.00 & 0.967 & 295 & 3.57 & 0.077 \\
\hline$B^{2}$ & 0.373 & 0.44 & 0.518 & 944.1 & 3.59 & 0.076 \\
\hline$C^{2}$ & 1.364 & 2.19 & 0.158 & 417.3 & 3.75 & 0.071 \\
\hline$D^{2}$ & 8.477 & 4.38 & 0.053 & 593.5 & 2.98 & 0.103 \\
\hline$A^{*} B$ & 0.600 & 0.31 & 0.585 & 53.9 & 0.27 & 0.610 \\
\hline$A^{*} C$ & 0.140 & 0.07 & 0.791 & 33.4 & 0.17 & 0.688 \\
\hline$A^{*} D$ & 3.515 & 1.81 & 0.197 & 0.4 & 0.00 & 0.964 \\
\hline$B^{*} C$ & 8.555 & 4.42 & 0.052 & 99.4 & 0.50 & 0.490 \\
\hline$B^{*} D$ & 6.890 & 3.56 & 0.078 & 94 & 0.47 & 0.502 \\
\hline$C^{*} D$ & 2.175 & 1.12 & 0.305 & 48.9 & 0.25 & 0.627 \\
\hline
\end{tabular}

Significant factors were in italics

The production of melanin was enhanced under light conditions where the pigment was known to absorb light in a wide range of wavelengths, including the UV region, and the intensity of absorption decreases slowly when wavelengths increase (Meredith and Sarna 2006; Gessler et al. 2014). Melanin has the ability to absorb light energy and convert photon energy into heat energy that promotes growth (Riesz et al. 2006). Scaling up the process from the shake flask level to bioreactor level showed an increase in melanin productivity up to $228 \mathrm{mg} / \mathrm{l}$. The maximum yield of melanin was achieved after $96 \mathrm{~h}$ from inoculating the reactor.

\section{UV protection of $B$. thuringiensis subsp. aegypti (Bt-C18) toxins}

B. thuringiensis is one of the most effective biological control agents used in agriculture bio-control though the main barrier facing its vigorous application is that most of the B. thuringiensis formulation is unstable under field conditions, due to the ultraviolet radiation in sunlight (Sansinenea et al. 2015).

In this experiment, the insecticidal activity of B.thuringiensis subsp. aegypti (Bt-C18) was investigated for controlling the population of cotton worm S. littroalis. The result of bioassay revealed that DHN melanin extracted from $H$. werneckii EGYNDA08 aids Bt-C18 to survive the direct exposure to light conditions in comparison to the dark conditions and the effect of light on Bt-C18 only without melanin (Table 6).

As shown in Table 6, the addition of melanin to $B t-C 18$ had protected it against the inactivation of sunlight and played a powerful role preventing the harmful effect of UV radiation. Trials R1, R2, and R3 had shown that the mortality of cotton worm was increased in the presence of melanin in contrast with the presence of Bt-C18 only. Although melanin was added in minimum

Table 5 The matrix and calculated responses for two-level FFD

\begin{tabular}{|c|c|c|c|c|c|c|}
\hline \multirow[t]{3}{*}{ Run } & \multicolumn{2}{|l|}{ Variables } & \multicolumn{4}{|l|}{ Responses } \\
\hline & \multirow[t]{2}{*}{ Brightness } & \multirow[t]{2}{*}{ Intensity } & \multicolumn{3}{|c|}{ Growth of the isolate } & \multirow{2}{*}{$\begin{array}{l}\text { Melanin } \\
\text { yield } \\
(\mathrm{mg} / \mathrm{l})\end{array}$} \\
\hline & & & O.D (600 nm) & Dry weight $(\mathrm{g} / \mathrm{l})$ & Final $\mathrm{pH}$ & \\
\hline 1 & 1 & -1 & 9.07 & 4.5 & 5.7 & 150 \\
\hline 2 & -1 & 1 & 7.83 & 5.5 & 6.2 & 100 \\
\hline 3 & 0 & 0 & 19.66 & 10 & 7.7 & 220 \\
\hline 4 & 1 & 1 & 13.57 & 5 & 5.7 & 160 \\
\hline 5 & -1 & -1 & 4.13 & 4.2 & 5.6 & 90 \\
\hline
\end{tabular}

The highest response were estimated and in italics 

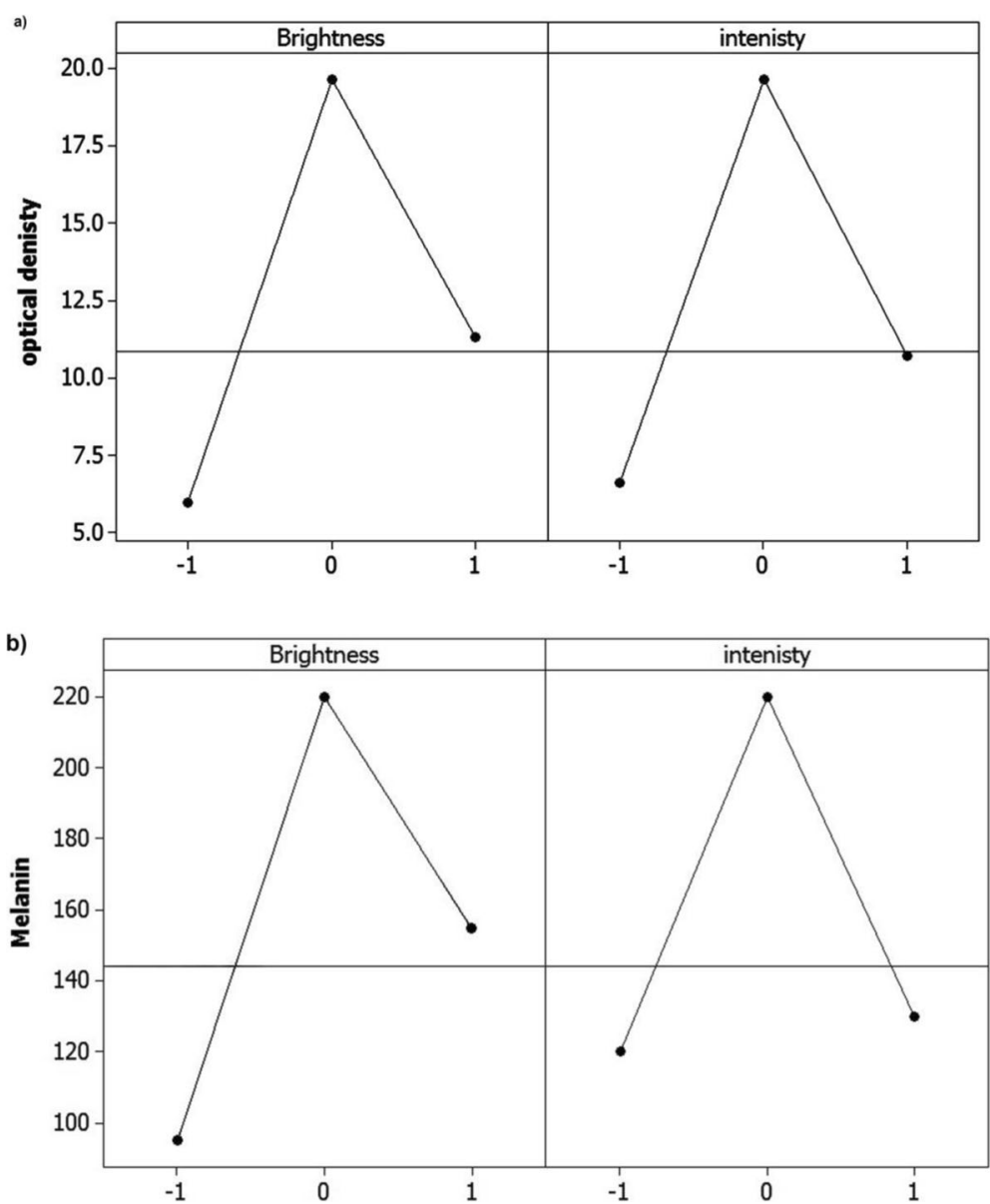

Fig. 3 Main effect plots showing optimum brightness and intensity affected on a optical density and $\mathbf{b}$ production of melanin by Hortaea werneckii EGYNDA08

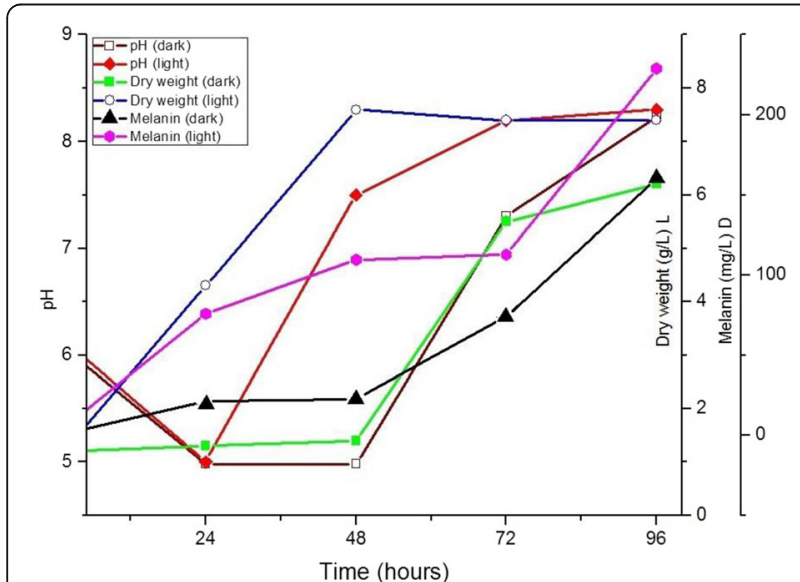

Fig. 4 Time trajectory showing the growth, melanin yield, and $\mathrm{pH}$ variation for the tested microbe Hortaea werneckii EGYNDA08 under both light and dark conditions concentration (5 ppm), but it showed a great effect that increased by increasing melanin concentration until it showed higher effect than Bt-C18 in dark conditions.

The insecticidal activity of $B$. thuringiensis strain $B t-C 18$ was assayed with and without melanin in different concentrations $(5,10$, and $15 \mathrm{ppm})$ after light exposure and in dark conditions on S. littrolis. DHN melanin extracted from $H$. werneckii EGYNDA08 was supplied to $B t$ formulations and subjected to light to detect the effect of melanin on protection of bioinsecticide.

Exposure of Bt-C18 into light and dark conditions without melanin indicated that light conditions showed lethal effect on $\mathrm{Bt}$-C18 and its insecticidal potential against $\mathrm{S}$. littoralis was decreased in contrast with its role in dark conditions; this result confirmed that sunlight have a negative effect on lethal of $B t$ (Brar et al. 2006). On the other hand, when DHN melanin was supplied to Bt-C18, the effect of bioinsecticide was maximized and the number of pathogenic larvae of $S$. littoralis was decreased. Melanin in minimum concentration $(5 \mathrm{ppm})$ had a major effect in protection of bioinsecticide from light and UV and gave it 
Table 6 UV protection of bioinsecticide by DHN melanin

\begin{tabular}{|c|c|c|c|c|c|c|c|c|c|c|c|c|}
\hline \multicolumn{3}{|c|}{ Control insects } & \multicolumn{10}{|l|}{ Test } \\
\hline & & & \multirow{2}{*}{\multicolumn{2}{|c|}{ Bt-C18 in dark }} & \multicolumn{8}{|c|}{ Bt-C18 exposed to sunlight } \\
\hline & & & & & \multicolumn{2}{|l|}{$\mathrm{Bt}-\mathrm{C} 18$} & \multicolumn{2}{|c|}{$\begin{array}{l}\text { Bt-C18+ melanin } \\
(5 \mathrm{ppm})\end{array}$} & \multicolumn{2}{|c|}{$\begin{array}{l}\text { Bt-C18 + melanin } \\
(10 \text { ppm) }\end{array}$} & \multicolumn{2}{|c|}{$\begin{array}{l}\text { Bt-C18+ melanin } \\
(15 \text { ppm) }\end{array}$} \\
\hline & Dead & Alive & Dead & Alive & Dead & Alive & Dead & Alive & Dead & Alive & Dead & Alive \\
\hline R1 & $0 \pm 0$ & $10 \pm 0$ & $6.6 \pm 1.15$ & $3.3 \pm 1.15$ & $5.6 \pm 0.57$ & $4.3 \pm 0.57$ & $7 \pm 1$ & $3 \pm 1$ & $8.3 \pm 0.57$ & $1.6 \pm 0.57$ & $8 \pm 0$ & $2 \pm 0$ \\
\hline R2 & $1.33 \pm 0.57$ & $8.6 \pm 0.57$ & $6.6 \pm 1.15$ & $3.3 \pm 1.15$ & $5.6 \pm 0.57$ & $4.3 \pm 0.57$ & $8 \pm 0$ & $2 \pm 0$ & $8.6 \pm 0.57$ & $1.3 \pm 0.57$ & $7.3 \pm 1.15$ & $2.6 \pm 1.15$ \\
\hline R3 & $1 \pm 0$ & $9 \pm 0$ & $7.3 \pm 1.15$ & $2.6 \pm 1.15$ & $6.6 \pm 1.15$ & $3.3 \pm 1.15$ & $7.3 \pm 0.57$ & $2.6 \pm 0.57$ & $9 \pm 1$ & $1 \pm 0$ & $9 \pm 0$ & $1 \pm 0$ \\
\hline
\end{tabular}

the ability to perform its function as bioinsecticide; when melanin concentration increased to 10 and 15 ppm, its role was maximized and toxicity of $\mathrm{Bt}-\mathrm{C} 18$ was increased. Melanin was proven to be a potential natural bioprotectant for $B t$ formulas which is in line with the work performed by Sansinenea and Ortiz (2015).

Further work is needed to understand the real mechanisms behind the responses of the yeast to the different nutritional, physical and light/darkness conditions on growth, and melanin production.

\section{Conclusions}

A black yeast strain was isolated from halophilic habitat in northern Egypt, and it was identified as Hortaea werneckii EGYNDA08. Its melanin proved to be a strong radioprotectant to $B$. thuringiensis (Bt-C18)-based biopesticides. This supports the notion that microbial melanin can reasonably replace chemical radioprotectants making the pest control via $B$. thuringiensis (Bt-C18)-based biopesticide a greener process.

The growth and productivity of this unicellular fungus was optimized to produce the black melanin using cheap media components via two-level factorial design. The most potential components were subsequently subjected to response surface methodology which maximized the productivity of melanin. Surprisingly, light (brightness and intensity) and darkness duration resulted in increasing melanin productivity up to $228 \mathrm{mg} /$ 1 under light conditions.

\section{Acknowledgements}

The authors would like to express their deepest gratitude to Dr. Amr Mowafey (associate professor of plant biotechnology, Faculty of Science, Mansoura University, Egypt) for his assistance with this study.

\section{Authors' contributions}

All authors contributed equally and they all read and approved the final manuscript.

\section{Ethics approval and consent to participate}

Not applicable

\section{Consent for publication}

The agreement of publication was taken, and as a corresponding author, I confirm that.
Competing interests

The authors declare that they have no competing interests.

\section{Publisher's Note}

Springer Nature remains neutral with regard to jurisdictional claims in published maps and institutional affiliations.

\section{Author details}

'Botany Department, Faculty of Science, Mansoura University, Mansoura 355111, Egypt. ${ }^{2}$ Agriculture Research Center (ARC), Agricultural Genetic Engineering Research Institute (AGERI), Giza, Egypt

Received: 2 March 2018 Accepted: 23 August 2018 Published online: 06 September 2018

\section{References}

Akilandeswari P, Pradeep B (2016) Exploration of industrially important pigments from soil fungi. Appl Microbiol Biotechnol 100:1631-1643

Bajaj IB, Lele SS, Singhal R (2009) A statistical approach to optimization of fermentative production of poly (y-glutamic acid) from Bacillus licheniformis NCIM 2324. Bioresour Technol 100:826-832

Brar SK, Verma M, Tyagi R, Valéro J (2006) Recent advances in downstream processing and formulations of Bacillus thuringiensis based biopesticides. Process Biochem 41: 323-342

Butler MJ, Lachance M-A (1987) Inhibition of melanin synthesis in the black yeast Phaeococcomyces sp. by growth on low $\mathrm{pH}$ ascorbate medium: production of spheroplasts from "albinized" cells. Can J Microbiol 33:184-187

d'schia M et al (2015) Melanins and melanogenesis: from pigment cells to human health and technological applications. Pigment Cell Melanoma Res 28:520-544

El Naggar AM, El Sayed HA, Elsalamony RA, Elrazak AA (2015) Biomass to fuel gas conversion through a low pyrolysis temperature induced by gamma radiation: an experimental and simulative study. RSC Adv 5:77897-77905

Elrazak AA, Ward AC, Glassey J (2013) Response surface methodology for optimising the culture conditions for eicosapentaenoic acid production by marine bacteria. J Ind Microbiol Biotechnol 40(5):477-487

Elsayed A, Mowafy AM, Soliman HM, Gebreil A, Magdy NI (2016) Characterization of new strains of Hortaea werneckii isolated from salt marshes of Egypt. Egypt J Basic Applied Sci 3:350-356

Gadd G (1982) Effects of media composition and light on colony differentiation and melanin synthesis in Microdochium bolleyi. Trans Br Mycol Soc 78:115-122

Garcia-Pichel F, Castenholz RW (1991) Characterization and biological implications of scytonemin, a cyanobacterial sheath pigment. J Phycol 27: 395-409

Garcia-Pichel F, Castenholz RW (1993) Occurrence of UV-absorbing, mycosporinelike compounds among cyanobacterial isolates and an estimate of their screening capacity. Appl Environ Microbiol 59:163-169

Gessler N, Egorova A, Belozerskaya T (2014) Melanin pigments of fungi under extreme environmental conditions (review). Appl Biochem Microbiol 50:105-113

Gunde-Cimerman N, Zalar P, de Hoog S, Plemenitaš A (2000) Hypersaline waters in salterns-natural ecological niches for halophilic black yeasts. FEMS Microbiol Ecol 32:235-240

Jacobson ES, Hove E, Emery HS (1995) Antioxidant function of melanin in black fungi. Infect Immun 63:4944-4945 
Kogej T, Wheeler MH, Rižner TL, Gunde-Cimerman N (2004) Evidence for 1, 8dihydroxynaphthalene melanin in three halophilic black yeasts grown under saline and non-saline conditions. FEMS Microbiol Lett 232:203-209

Kollias N, Sayre RM, Zeise L, Chedekel M (1991) New trends in photobiology (invited review). J Photochem Photobiol A: Chem 9:135ą160

Kumar A, Vishwakarma HS, Singh J, Dwivedi S, Kumar M (2015) Microbial pigments: production and their applications in various industries. Int J Pharmaceutical Chem Biol Sci 5:203-212

Kurbanoglu EB, Kurbanoglu NI (2004) Ram horn peptone as a source of citric acid production by Aspergillus niger, with a process. J Ind Microbiol Biotechnol 31: 289-294

Kutty S, Lawman D, Singh I, Philip R (2013) Black yeasts from the slope sediments of Bay of Bengal: phylogenetic and functional characterization. Mycosphere 4:346-361

Kutty SN (2009) Marine yeasts from the slope sediments of Arabian Sea and Bay of Bengal PhD thesis. In: Cochin University of Science \& Technology

Meredith P, Sarna T (2006) The physical and chemical properties of eumelanin. Pigment Cell Res 19:572-594

Montgomery DC (2008) Applications of design of experiments in engineering. Qual Reliab Engng Int 24:501-2. https://doi.org/10.1002/qre.969.

Osman YA, El-Morsi AA, Elwakil MA, Omer FH (2014) Five distinctive phages from an Egyptian industrial strain of Bacillus thuringiensis subsp. aegypti. J Environ Sci Technol 7(1):67

Pombeiro-Sponchiado SR, Sousa GS, Andrade JC, Lisboa HF, Gonçalves RC (2017) Production of melanin pigment by fungi and its biotechnological applications. In: Melanin. InTech

Ravishankar J, Muruganandam V, Suryanarayanan T (1995) Isolation and characterization of melanin from a marine fungus. Bot Mar 38:413-416

Riesz J, Gilmore J, Meredith P (2006) Quantitative scattering of melanin solutions. Biophys J 90:4137-4144

Rosas ÁL, Casadevall A (1997) Melanization affects susceptibility of Cryptococcus neoformans to heat and cold. FEMS Microbiol Lett 153:265-272

Sangkharak K, Prasertsan P (2007) Optimization of polyhydroxybutyrate production from a wild type and two mutant strains of Rhodobacter sphaeroides using statistical method. J Biotechnol 132:331-340

Sansinenea E, Ortiz A (2015) Melanin: a photoprotection for Bacillus thuringiensis based biopesticides. Biotechnol Lett 37(3):483-490

Sansinenea E, Salazar F, Ramirez M, Ortiz A (2015) An Ultra-Violet Tolerant WildType Strain of Melanin-Producing Bacillus thuringiensis. J Microbiol 8(7): e20910. https://doi.org/10.5812/jjm.20910v2.

Schweitzer AD et al (2010) Melanin-covered nanoparticles for protection of bone marrow during radiation therapy of cancer. Int I Radiat Oncol Biol Phys 78: 1494-1502

Solano F (2014) Melanins: Skin Pigments and Much More—Types, Structural Models, Biological Functions, and Formation Routes. New J Sci 28:498276. https://doi.org/10.1155/2014/498276

Paech K, Tracey MV (2013) Modern Methods of Plant Analysis/Moderne Methoden der Pflanzenanalyse. Springer Sci Business Media 2: https://doi. org/10.1007/978-3-642-64961-5.

Youngchim S, Morris-Jones R, Hay RJ, Hamilton AJ (2004) Production of melanin by Aspergillus fumigatus. J Med Microbiol 53:175-181

Zalar P, Novak M, De Hoog G, Gunde-Cimerman N (2011) Dishwashers-a manmade ecological niche accommodating human opportunistic fungal pathogens. Fungal Biol 115:997-1007

Zhdanova NN, Zakharchenko VA, Vember W, Nakonechnaya LT (2000) Fungi from Chernobyl: mycobiota of the inner regions of the containment structures of the damaged nuclear reactor. Mycol Res 104:1421-1426

\section{Submit your manuscript to a SpringerOpen ${ }^{\circ}$ journal and benefit from:}

- Convenient online submission

- Rigorous peer review

- Open access: articles freely available online

- High visibility within the field

- Retaining the copyright to your article

Submit your next manuscript at $\boldsymbol{\nabla}$ springeropen.com 